\title{
Flipped Training-A New Teaching Model for Engineering Training
}

\author{
Liu Xiang; Wang Lei; Cao Jianghua \\ Engineering training centre \\ Wuhan University of Science and Technology \\ Wuhan, China 430065 \\ liuxiang@wust.edu.cn
}

\author{
Xia Xuhui* \\ Engineering training centre \& School of Machinery \& \\ Automation \\ Wuhan University of Science and Technology \\ Wuhan, China 430065
}

\begin{abstract}
Aiming to solve the problems which exist in college engineering training teaching, this paper puts forward a new teaching idea of "flipped training", expounds connotation, characteristics and elements of "flipped training", and analyzes supporting conditions for implementation of "flipped training", thus providing a new way of thinking for teaching reform in engineering training under the new situation.
\end{abstract}

Keywords-engineering training; flipped training; practice teaching; innovation ability

\section{INTRODUCTION}

With the rapid economic and social development, industrial entities have increasing demand for high-level engineering and technical personnel. Level of innovation ability is the most important indicator to measure qualification of engineering and technical personnel. As the cradle of cultivating engineering and technical talents, engineering colleges and universities should establish a high degree of responsibility consciousness and constantly improve quality of engineering education. In recent years, national education authorities have launched a series of wide-scaled, influential, largely beneficial teaching reform projects, such as: "undergraduate teaching quality and teaching reform project in higher institutions", "excellent engineer education and training program", etc. The purpose is to require colleges and universities to focus on cultivating students' engineering awareness and engineering innovative practice ability. Under the guidance of these macroeconomic policies, teachers engaged in engineering education and engineering education researchers have carried out in-depth research on the hot topic of "cultivating and enhancing engineering innovation ability", making a series of achievements[1][2]. However, these research results are mainly concentrated in engineering classroom teaching, less oriented to engineering practice teaching.

Engineering training aims to cultivate students' engineering practice ability, innovation ability and team spirit. In teaching activities, it focuses on unity of knowledge and action, emphasizes integration of disciplines, respects personality development and stimulates innovative thinking, which plays an irreplaceable role in cultivation of high-quality engineering innovation talents [3]. But due to problems encountered in the development process of China's engineering training center, the important role of engineering training in engineering and technical personnel training has not yet fully revealed [4], and the majority of teaching researchers lack attention to and depth in the study. Under the background that intelligent manufacturing, digital manufacturing, green manufacturing, Internet of things emerge endlessly, macroeconomic strategies such as "China Industrial 4.0", "Made in China 2025" are successively put forward, engineering training should seize this round of teaching reform opportunities, take cultivation of students' engineering innovation ability as the guide, stimulate students' autonomy and initiative, construct and implement individual training mode in practical teaching of engineering training, teach students in accordance with their aptitude, to provide a broad development space for students' unique and innovative design and engineering practice.

At present, the following problems exist in engineering training teaching of colleges and universities. (1) Focus on theory, knowledge and commonality, while ignoring practice, ability and personality. Teachers only act as the role of knowledge presenter in the teaching process, and fail to take the responsibility of guiding students in development of practical ability. In addition, the same teaching methods, contents and patterns are adopted for students of different majors, different levels and different knowledge structures, ignoring shaping of students' personality. (2) The number of engineering training equipment and the number of students are seriously out of tune. Since the late nineties of last century, higher education in our country shows increasingly obvious trend of popularization, with number of college students in school constantly updated. As engineering training is a practical teaching link for the whole school, a huge number of students are involved, plus it also concerns multiple disciplines including machinery, electronic, computer, automation, etc., equipment purchase and maintenance costs required for engineering training are considerable. Within limited teaching funding, number of equipment for students will be inevitably lowered. (3) Efforts to cultivate and improve students' engineering innovation ability are still insufficient. Engineering training center has a lot to do in integrating interdisciplinary teaching resources in the school, guiding students to form innovative team with multi-disciplinary integration and holding entrepreneurship lectures and seminars, etc.

In order to solve the above problems, the author draws on successful experience of "flipped classroom" in teaching

This paper is supported by Hubei provincial teaching and research project in higher institutions (No. 2015239); Hubei provincial teaching and research project in higher institutions (No. 2015226); 2015 Wuhan University of Science and Technology Teaching and Research Project (No. 2015z002); 
reform at home and abroad, puts forward the concept of "flipped training" in engineering training teaching, and introduces teaching design based on practical teaching mode of "flipped training" and its supporting measures, in a effort to make a new exploration into cultivation of innovative engineering and technical personnel.

\section{CONNOTATION AND CHARACTERISTICS OF "FLIPPED TRAINING"}

"Flipped training", a new concept derived from "flipped classroom", has some similarities with "flipped classroom" in the form, but has its unique connotation and characteristics. "Flipped Classroom" originated in 2007 from an attempt by teachers Jon Bergmann and Aaron Sams in "Forest Park" High School, Colorado, the United States to make up classes for students unable to attend the class by sharing the recording of the course video online for students to download and study [5]. In recent years, with the development of information technology and computer technology, "flipped classroom" quickly spreads throughout the world and attracts attention from more and more education researchers. "Flipped classroom" means a new teaching model in which teachers provide teaching video, students watch, study contents of the video before class, then carry out targeted exercises; and then students cooperate in the classroom, teachers and students make interaction to complete knowledge internalization through problem-solving [6]. Engineering training has its peculiarity different from other courses, and its teaching process is mainly completed in simulation environment of laboratory or industrial scene. Therefore, "flipped training" refers to: a new training model in which teachers provide teaching video, virtual simulation equipment and assembly software as the main form of learning resources, students watch the video before the class, use virtual learning resources to complete task simulation, and conduct collaborative research with other students in the classroom, while teachers and students communicate with each other to complete an engineering project covering the product life cycle.

The teaching process of "flipped training" is divided into three stages. The first stage: the teacher raises questions according to the teaching objectives, students find ways to solve the problem through watching the video, employ simulation and virtual assembly to verify conclusions and have access to intuitive experience of equipment operation; the second stage: Complete knowledge internalization and operation skills acquisition through appropriate and necessary field equipment operation training, in this stage, the teacher provides targeted one-to-one demonstration and guidance to students, answers their questions that occur in video watching and simulation practice, and provides one-time solution to students' common questions; The third stage: encourage and instruct students to carry out in-depth thinking and creative practice, or exploratory practice on a practical project, so that students build engineering awareness in the process of "learning - verification - training - thinking - retraining innovation", and cultivate engineering innovation ability.

From the above analysis, it is not difficult to see that, compared with traditional concept of engineering training teaching, the innovative teaching philosophy of "flipped training" has the following characteristics:

First, respect for students' "personalized" learning needs. "Personalized" learning needs include choice of learning time, location, content and methods. In traditional engineering training, these aspects are determined by the school's academic department, and students are forced by credit and pressure of graduation to passively complete the imposed learning tasks. Then, students' enthusiasm for training is greatly affected, as they cannot mobilize enthusiasm of learning. In this case, the purpose of student practice is simply to get credit for successful graduation, so it is difficult for them to carry out creative engineering training activities. "Flipped training" model breaks through space constraints in student training, as academic department only provides the deadline for training, and training activities and contents will be arranged by oneself during this period according to their own interests, expertise and knowledge structure, so that students become their own learning guider.

Second, advocate "student-centered" classroom model. "Flipped training" emphasizes that students conduct meaningful cooperative exploration practice in the classroom, while teachers inspire students' innovative thinking, and guide students into deep thinking and practice. Students and teachers have plenty of time to interact in the teaching site, so that students can communicate with teachers in the first time when they encounter technical problems and a variety of unexpected situations in completion of project activities. After these problems are solved, students' interest in practice and confidence will grow, which ultimately lays a solid foundation for students to carry out creative practice.

Third, encourage students to carry out "cooperative" exploration practice. Cooperative learning has a special effect in promoting cognitive and skill development. In the "flipped training" mode, every three students form a project team. The team members have both division of labor and concentrated discussion on experience, feelings, ideas and problems encountered in the training process, finding technical route to solve the problems in discussions and igniting spark of innovation in the collision of thinking. Teachers play the role of maintaining efficient discussions among the team members, assisting to solve some technical problems and encouraging students' lateral thinking. Through "cooperative" practice, students may experience the team's strong cohesive effect, and gradually establish team awareness in engineering practice.

Fourth, carry out practical teaching activities with modern information education technology. In "flipped classroom", teacher courseware and video production, as well as students' video watching through the network reflects the great role of information education technology in practical teaching. Moreover, "flipped training" also includes a large number of presentations, cases, simulations, virtual operations, etc. which requires that "flipped training" should focus on building virtual simulation network platform on the basis of curriculum network platform of "flipped classroom", to integrate processing virtual simulation, machine motion simulation, machine virtual assembly, CAD / CAM, etc [7]. into the platform, so that, through organic combination between 
curriculum platform and simulation platform, restrictions of equipment and venues on student practice and innovation activities can be broken through, to realize a real "flip" of identity of students and teachers.

\section{THE BASIC ELEMENTS OF "FLIPPED TRAINING"}

\section{A. Production of video and courseware}

First of all, teachers should make choice of teaching contents based on students' knowledge structure and operational ability, and prioritize basic, memory, understanding knowledge and skills as content of teaching video, while strong theoretical knowledge should not be presented to students in the form of video. Second, video recording time should not be too long, to avoid that students are unable to focus attention during watching. Survey shows that $64.9 \%$ of students believe that video should be controlled within about 20 minutes [8]. This requires the teacher to "fragment" the contents after determining video teaching content, so that content of a video is only corresponding to a knowledge point or an action skill. Furthermore, produce courseware that inspires students' thinking. Courseware serves as "adhesives" of "fragmented" knowledge. Knowledge "fragmentation" is a means of quick access to new knowledge in a short period of time, but "fragmented" knowledge is not conducive to students' breakthrough in innovation in cooperative explorative practice in the later period. Only when "fragmented" knowledge is resorted and integrated to form complete knowledge structure can it lays the foundation for creative practice. Finally, production of video and courseware should reflect peopleorientation. Video and courseware is ultimately for students' self-study before class, so teachers should take full account of students' interests while producing video and courseware. For example, in the design of courseware, teacher should take full account of resolution of students' receiver terminal display to set courseware font and color; network status of student network terminal equipment and students' cost of surfing the internet, to select appropriate code rate compression scheme for the video production, etc.

\section{B. On-site practical operation}

Although in pre-class self-study stage, students have observed practical operation mode through watching the video, and have experienced the operation process via simulation operation software, these cannot fundamentally replace actual practical operation. On-site operation is not only a test of learning effect after watching the video, but also an important means for teachers to find and correct students' mistakes. As students have conducted relevant operation in the virtual environment before class, and mastered the operating points, teachers should encourage students to complete operation independently under the premise of ensuring safety of students and normal operation of equipment. At the same time, teachers should give timely and targeted help for the problems students encounter in pre-class simulation or classroom operation. In addition, the teacher should organize each group of students to make summary of practice, intensively display practice result of each group, let the team members to comment on each other's actual results, and make pertinent evaluation and improvement suggestions for students' practical activities. Finally, teachers should also help students sort out a reasonable view from technical line, processing programs offered by the parties, so that students can better internalize the experiences, technology and ability gained in practice into their own knowledge structure.

\section{Carry out cooperative project practice study}

Project-based cooperative learning serves as a sublimation of "flipped training" mode for practical operation, also an important means to enhance students' practical ability of engineering innovation. First of all, content of practical activities is development project based on industrial products. In practical activities, team members are organized to start a series of activities like demand analysis, program design, processing method design, cost analysis with project as the carrier, around whole process of product life cycle and based on results of previous practice. Teachers should actively participate in discussion of student teams, strengthen interaction between teachers and students, timely give encouraging evaluation on views, ideas proposed by students, enhance students' self-confidence, so that they feel their views and ideas are based on their own conclusions of preliminary video learning and practice test, experiencing sense of achievement of unity of knowledge and action. Second, teachers should try to integrate students of different subject backgrounds and different interests in the same training group, which helps the team members to give play to their own expertise and lays a solid foundation for cooperative practice. Furthermore, in the process of cooperative learning, teachers should create atmosphere of benign competition within the group. A person may be unable to understand many things, but may achieve more understanding through cooperative learning and exchange of ideas. The benign interaction and competition in the study is conducive to inspiring learning motivation. At the same time, young people, with unbound personality and uninhibited character, may easily ignite sparks of innovation. Finally, teachers should listen to practical study report of the cooperative group. The team members summarize the results of recent practice, including not only results achieved and reports of supporting materials, but also difficulties and unresolved problems encountered in the previous phase. The common problems can be solved in the whole class via collective discussion.

\section{Feedback and summary}

"Flipped training" model, as a new practice teaching model, lacks mature experience for reference. Therefore, we need to widely collect students' experience and recommendations after school, to help teachers improve teaching methods and teaching quality. In evaluation of student learning effect, a questionnaire should be designed to understand students' experience and ideas of practice, solicit students' requirements to modify "flipped training" video and courseware, to further optimize the content of cooperative practice and seek innovation in multiple aspects like theory, program, design, processing, operation, etc. 


\section{SUPPORTING CONDITIONS FOR "FLIPPED TRAINING"}

\section{A. Information technology supports}

"Flipped training" requires an interactive, unobtrusive network platform that hosts course learning materials such as video, courseware, etc. In addition, a real-time learning forum community is also very important. The forum should offer students on-line help to solve problems encountered in videowatching and courseware learning, so that students receive effective learning guidance. In addition, to broaden students' horizon, "flipped training" course platform should also provide a wealth of information resources to facilitate students to inquire cutting edge dynamics of related technical issues, and expand the breadth of learning. Virtual simulation resources can also be shared through the network platform, while helps students independently use simulation resources to carry out independent investigative practice. Therefore, whether there is strong modern information technology education as a support is the most important and most basic supporting condition for smooth implementation of "flipped training".

\section{B. Renewal of teachers' knowledge structure}

"Flipped training" model is to carry out student-centered practice teaching activity, so students' conclusions after data inquiry or collective research and discussion are often unknown, and may go beyond teachers' own knowledge scope. Only by strengthening professional learning, paying attention to cutting-edge development of engineering technology, constantly updating and improving their knowledge structure can teachers give appropriate comments or make reasonable modification opinions on students' conclusions or questions. It can be seen that teachers' knowledge structure is a condition that decides depth and teaching effect of "flipped training".

\section{Improvement of teaching methods}

"Flipped training" advocates cooperative project-based practice learning to cultivate and improve students' engineering innovation ability, so teachers' teaching methods must adapt to this new requirement. Teachers should strengthen study of teaching methods, make every cooperative student truly integrate into the team, and give play to their own strength in the team, rather than wait for other members' ready results. It can be seen that teachers' teaching methods determine whether "flipped training" can be carried out efficiently and continuously in the classroom.

\section{CONCLUSION}

Innovation ability is trainable, and engineering innovation ability needs to be cultivated via repeated training. In order to cultivate students' engineering practice ability and innovation ability, we start from engineering training, draw successful experience of "flipped classroom", and put forward the new concept of "flipped training", which explores a new way for training and cultivation of engineering innovation ability of college students.

\section{ACKNOWLEDGMENT}

The first author wishes to acknowledge the financial support of Hubei provincial teaching and research project in higher institutions (No. 2015239); Hubei provincial teaching and research project in higher institutions (No. 2015226); 2015 Wuhan University of Science and Technology Teaching and Research Project (No. 2015z002); Thanks for all the authors of the references who gives us inspirations and helps. The authors are grateful to the editors and anonymous reviewers for their valuables comments that improved the quality of this paper.

\section{REFERENCES}

[1] JIANG Jin-hua, "Exploration of scientific and technological innovation of undergraduates and management modes of open laboratory," Research and exploration in laboratory. vol. 28, no. 12, Dec. 2009, pp. $12-15$, in press.(in Chinese)

[2] LU Xiao-min, KAN Xu-ping, ZHU Hua-bing, "Study on 'discovery type' practical teaching mode," Experimental technology and management. vol. 32, no. 1, Jan. 2015, pp.41-44, in press. (in Chinese)

[3] ZHAO Yang, PENG Zhi-guang, "Construction and practice of engineering training centre in some universities with vocation character," Research and exploration in laboratory. vol. 27, no. 11, Nov. 2008, pp. 79-81, in press. (in Chinese)

[4] LIANG Yan-de, "Construction and development of engineering training centres in colleges and universities," Experimental technology and management. vol. 30, no. 6, Jun. 2013, pp. 6-8, in press. (in Chinese)

[5] HUANG Yan, JIANG Ling, HUANG Lei, "The application research on flipped classroom model in experimental course of 'Modern educational technology'," China educational technology. no. 4, Apr. 2014, pp. 110114 , in press. (in Chinese)

[6] ZENG Ming-xing, ZHOU Qing-ping, CAI Guo-min, WANG XIAO-bo, CHEN Sheng-ping, HUANG Yun, et al, "Research of flipped classroom teaching model based on MOOC," China educational technology. no. 4, Apr. 2015, pp. 102-108, in press. (in Chinese)

[7] LI Cui-chao, LING Fang, "Application of virtual simulation technology in engeering training," Laboratory science. vol. 18, no. 2, apr. 2015, pp. $128-131$, in press. (in Chinese)

[8] QI Jun, "The rise, development and process design of "flipped classroom' in US and its implication," Comparative education review. no. 1,2015 ,pp. 21-27, in press. (in Chinese) 